\title{
Factors Influencing Adolescent Blood Pressure: The Debrecen Hypertension Study
}

\author{
Éva Katona ${ }^{a}$ Miklós Zrínyi $^{d}$ Eva Komonyi $^{\mathrm{a}}$ Szabolcs Lengyel ${ }^{\mathrm{a}}$ György Paragh ${ }^{\mathrm{a}}$ \\ János Zatik ${ }^{c}$ Béla Fülesdi ${ }^{b}$ Dénes Páll ${ }^{a}$ \\ a 1st Department of Medicine, and bepartment of Anaesthesiology and Intensive Care, Medical and \\ Health Center, and 'Department of Obstetrics and Gynecology, University of Debrecen, Debrecen, Hungary; \\ dWorld Health Organisation, Geneva, Switzerland
}

\section{Key Words}

Epidemiology · Adolescent hypertension •

Population-based survey

\section{ypertension.}

\section{Abstract}

Aim: To obtain epidemiological data on the blood pressure (BP) status of high school students and factors influencing BP. Methods: Subjects filled out a questionnaire and three repeated BP measurements were taken. All high school attending students in Debrecen (final sample $n=10,194$, mean age $16.6 \pm 1.0$ years) participated in the study. Results: Boys had significantly higher systolic BP $(+11.3 \mathrm{~mm} \mathrm{Hg})$ and diastolic BP $(+2.2 \mathrm{~mm} \mathrm{Hg})$ than girls $(p<0.001)$. There was a positive correlation between weight and BP $\left(r_{\text {syst }}=0.42\right.$, $\left.r_{\text {diast }}=0.29\right)$, height and BP $\left(r_{\text {syst }}=0.33, r_{\text {diast }}=0.15\right)$, body mass index $(B M I)$ and $B P\left(r_{\text {syst }}=0.31, r_{\text {diast }}=0.27\right)$. Multiple regression analysis was used for statistical analysis. Gender $(\beta=0.36)$, BMI $(\beta=0.25)$, hypertension of parents (father $\beta=$ 0.04 and mother $\beta=0.02$ ), smoking, alcohol consumption and age determined systolic outcomes in descending order. For the diastolic model, BMI remained a strong determining factor $(\beta=0.25)$ and gender was also significant $(\beta=-0.09)$. Entering independents together accounted for $28.2 \%$ of the total variance in systolic and for $18.1 \%$ in diastolic BP. Conclu-

\section{KARGER}

Fax +41613061234

E-Mail karger@karger.ch

www.karger.com
(C) 2011 S. Karger AG, Basel

$1420-4096 / 11 / 0000-0000 \$ 38.00 / 0$

Accessible online at:

www.karger.com/kbr sion: Body weight is central to determining BP. Because that is an alterable cardiovascular risk factor, we presume that lifestyle modification will not only result in reduced weight, but also in decreased BP.

Copyright $\odot 2011$ S. Karger AG, Basel

\section{Introduction}

Evidence that essential hypertension may begin in childhood is now rather clear; however, the ability to measure blood pressure (BP) accurately and reliably in children and adolescents is a prerequisite for individuals with consistently high levels of BP $[1,2]$. The prevalence of hypertension in adolescence is markedly lower than in adulthood; about $1-1.5 \%$ of youngsters are affected [3]. Elevated BP is a risk factor for cardiovascular diseases regardless of its onset (adolescence or adulthood). In numerous cases, target organ damage could be verified in adolescence, too [4]. It is well known that there is a relationship between hypertension in adolescents and later manifestation in adulthood $[5,6]$. Moreover, the association is strongly increased with repeated measurements and standardized procedures [7].

Dénes Páll, MD, PhD

1st Department of Medicine, Medical and Health Center

University of Debrecen, Nagyerdei krt. 98

HU-4032 Debrecen (Hungary)

Tel. +36 309657 913, E-Mail pall.denes@ gmail.com 
To diagnose adolescent hypertension, repeated measurements on different occasions are needed because of the $\mathrm{BP}$ decrease observed in young people during the control measurements [8]. The actual BP is the mean value of three measurements following each other by a few minutes' difference $[2,3]$. Conditions and techniques of BP measurement are of great importance [9]. Similarly to childhood hypertension, adolescent hypertension is defined in epidemiological terms: values being +2 SD from the mean are accounted for as hypertension $[1,2]$.

Several factors are known to exert influence on BP in a given population. The most important factors that have emerged from the literature are as follows: (1) geographical location and ethnicity [10-13], (2) gender [3, 10, 14, 15], (3) age [10, 15], (4) weight and height [10, 11, 13-18], (5) inheritance $[19,20]$, (6) birth weight $[10,14,21-23]$, and (7) others (such as disadvantaged social conditions, smoking or drinking alcohol) $[14,15,23]$.

We are unaware of any representative 15 - to 18 -yearold population-based hypertension study either in Hungary or in Central-Eastern Europe to date. The objective of our investigation was to implement a populationbased, representative study on BP involving adolescents of Hungary, and - with the aid of a questionnaire - to gain epidemiological data on factors presumed to influence BP (e.g. gender, age, height, weight, positive family history, low birth weight, smoking, alcohol consumption, sports, salt intake, stress). We also attempted to determine the relative importance (weight) of these factors using a linear regression model.

\section{Subjects and Methods}

The study was carried out with the approval of the Local Medical Ethics Committee of the University of Debrecen, Medical and Health Science Center. We performed a 'pilot study' with $2 \%$ of the total planned population $(n=227)$. The general methodology of the study has already been presented in detail in previous publications $[9,24]$. Both the adolescent and one of the parents signed the informed consent forms.

\section{BP Measurements}

All measurements were taken in classrooms between 8 a.m. and 1 p.m. under standard circumstances. After $10 \mathrm{~min}$ of rest, $\mathrm{BP}$ was measured in the sitting position on the right arm using a validated Omron M4 digital oscillometric manometer (Omron Healthcare GmbH, Hamburg, Germany) $[25,26]$. If the forearm circumference was $34 \mathrm{~cm}$ or over, an obese cuff was used. Three measurements were performed in each case with 5-min intervals and the average values of the systolic and diastolic BP were used for further analysis.

\section{Questionnaire Parallel to BP Measurements}

After the adolescent and one of the parents signed the informed consent, they answered questions. The adolescents took the questionnaire home so they could discuss the answers with their parents. We used easily understandable questions, offering alternative answers to them. Before finalizing our questionnaire, we performed a pilot study in $2 \%$ of the aimed population $(\mathrm{n}=$ 218), and after that we made changes whenever it was necessary. Data of the pilot study are not shown in the final results.

We were looking for those variables which might potentially have affected BP. Gender and age (time elapsed between date of birth and time of examination) of the individuals were recorded. On every further question we also offered the possibility of the answer 'not known'.

Positive family history of hypertension (mother and/or father) was also assessed (yes vs. no). In order to study the potential influence of birth weights, two categories were established: low $(<2,500 \mathrm{~g})$ and normal birth weights $(\geq 2,500 \mathrm{~g})$. We also recorded excess salt intake (less than average, average, more than average). We tried to confirm the answer with the following question: 'Do you usually add some extra salt (table-salt) to your dishes?' - Never, sometimes or usually. For actual smoking habits we offered the following answers: never, occasionally, 1-10 cigarettes/day, 11-20 cigarettes/day or $>20$ cigarettes/day, regularly. We had a question also about alcohol drinking habits with the following answers: never, maximum on a monthly basis, on a weekly basis or several times per week. In order to get information about regular physical activity we asked: 'Do you do sports in your spare time?' - Offering the following answers: never, sometimes or regularly. Finally we raised the question, 'How frequently do you encounter stressful situations?' - Never, sometimes or frequently. These factors were later used in subsequent analyses as potential predictors of both elevated systolic and diastolic BP.

\section{Population Studied}

We performed all the above measurements in every secondary school student in Debrecen. Each student from 26 schools was approached and asked to join the study except for those who had been absent on the day of implementation. The final sample consisted of 10,359 adolescents, 22 individuals declined participation. We obtained full data (lifestyle survey, BP measures) for 10,213 individuals (98.59\%). At the outset of our survey, we found 19 $(0.002 \%)$ adolescents already diagnosed with and treated for hypertension. Their data were discarded from further analysis: we processed data for the remaining 10,194 individuals.

Body weight was recorded to the nearest $100 \mathrm{~g}$ using a calibrated standard beam balance scale with the subjects wearing light indoor clothing without shoes. Height was recorded to the nearest $0.5 \mathrm{~cm}$ using a standardized wall-mounted height board. Body mass index (BMI) was calculated as weight $(\mathrm{kg})$ divided by height in meters squared $\left(\mathrm{m}^{2}\right)$.

\section{Statistical Analysis}

Data were recorded by Access for Windows using a 'crosscheck' technique. Statistical analyses were done by SPSS Windows version 11.0. Descriptive statistics included mean, standard deviation and proportions (\%). For directional hypotheses, onetailed Pearson correlation coefficients were obtained ( $\chi^{2}$ test). In all other cases, two-tailed tests and repeated measures analysis of variance (ANOVA) were employed. We assessed normal sample 
Table 1. Epidemiological data on adolescents participating in the Debrecen Hypertension Study

\begin{tabular}{lcccc}
\hline Parameter examined & Total & Boys (B) & Girls (G) & p (B vs. G) \\
\hline Number & 10,194 & 5,163 & 5,031 & - \\
Age, years & $16.6 \pm 1.0$ & $16.6 \pm 1.0$ & $16.5 \pm 0.9$ & 0.345 \\
Height, cm & $171.7 \pm 8.8$ & $176.9 \pm 7.8$ & $166.3 \pm 6.1$ & $<0.001$ \\
Weight, kg & $61.6 \pm 11.7$ & $66.9 \pm 11.9$ & $56.2 \pm 8.6$ & $<0.001$ \\
BMI & $20.8 \pm 3.0$ & $21.3 \pm 3.2$ & $20.3 \pm 2.8$ & $<0.001$ \\
Hypertensive mother, \% & 10.8 & 9.0 & 12.6 & $<0.001$ \\
Hypertensive father, \% & 11.7 & 10.7 & 12.7 & $<0.001$ \\
Smoking, \% & 19.7 & 21.7 & 17.6 & $<0.001$ \\
Alcohol consumption, \% & 12.2 & 15.6 & 8.7 & $<0.001$ \\
Regular sport activity, \% & 31.9 & 41.0 & 22.6 & $<0.001$ \\
Frequent stress situations, \% & 11.2 & 7.4 & 15.2 & $<0.001$ \\
Excess salt intake, \% & 15.1 & 16.3 & 14.0 & 0.001 \\
Low birth weight, \% & 6.7 & 6.4 & 7.1 & 0.063 \\
Systolic BP, mm Hg & $116.9 \pm 14.2$ & $122.5 \pm 13.5$ & $111.2 \pm 12.5$ & $<0.001$ \\
Diastolic BP, mm Hg & $68.5 \pm 8.9$ & $69.6 \pm 8.9$ & $67.4 \pm 8.9$ & $<0.001$ \\
\hline
\end{tabular}

Table 2. Analysis of correlation between BP, age, height, weight and BMI

\begin{tabular}{lllll}
\hline Parameter & Age & Height & Weight & BMI \\
\hline Systolic BP & 0.06 & 0.33 & 0.42 & 0.31 \\
Diastolic BP & 0.06 & 0.15 & 0.29 & 0.27 \\
\hline
\end{tabular}

Results mark the 'r' value of Pearson's coefficient.
Table 3. Influence of family history and birth weight on BP

\begin{tabular}{llllll}
\hline & & Systolic BP & p & Diastolic BP & p \\
\hline $\begin{array}{l}\text { Mother's } \\
\text { hypertension }\end{array}$ & yes & $117.7 \pm 14.8$ & 0.063 & $69.4 \pm 9.1$ & 0.001 \\
\hline nather's & yes & $116.7 \pm 14.1$ & & $68.4 \pm 8.9$ & \\
hypertension & no & $116.8 \pm 14.0$ & 0.002 & $69.4 \pm 9.2$ & $<0.001$ \\
\hline Low birth weight & yes & $118.7 \pm 15.0$ & 0.024 & $68.5 \pm 8.9$ & 0.274 \\
$(<2,500$ g) & No & $116.9 \pm 14.1$ & & $68.2 \pm 9.4$ & \\
\hline
\end{tabular}

distribution, characteristics by visual aids (histograms) as well as with one-sample Kolmogorov-Smirnov tests. To indicate differences between groups, independent sample t tests were used. Multiple regression analysis was employed to predict systolic and diastolic BP. The level of significance was set at $5 \%$.

\section{Results}

Demographic variables of subjects are summarized in table 1. Mean BP for boys was significantly higher than that for girls (systolic BP $+11.3 \mathrm{~mm} \mathrm{Hg}, \mathrm{t}=43.7, \mathrm{p}<0.001$; diastolic $\mathrm{BP}+2.2 \mathrm{~mm} \mathrm{Hg}, \mathrm{t}=12.3, \mathrm{p}<0.001)$.

We compared the relationship among systolic and diastolic BP and age, height, weight and BMI. Significant associations were found: systolic BP had a stronger relationship with each variable than diastolic BP (table 2).
The strongest association was found between BP and weight $\left(r_{\text {syst }}=0.42, \mathrm{p}<0.001\right.$, and $\left.r_{\text {diast }}=0.29, \mathrm{p}<0.001\right)$. We also found a positive relationship between systolic BP and height, diastolic BP was associated with height to a lesser extent. There was also a positive correlation between BP and BMI ( $\mathrm{r}_{\text {syst }}=0.31, \mathrm{p}<0.001$, and $\mathrm{r}_{\text {diast }}=0.27$, $\mathrm{p}<0.001)$. Age and BP weakly correlated. Separate analyses revealed mild correlation between age and systolic BP for boys $\left(\mathrm{r}_{\text {syst }}=0.1, \mathrm{p}<0.001\right)$ but no such association existed for girls $\left(r_{\text {syst }}=-0.02, p>0.05\right)$. Similar results were available for diastolic BP, i.e. mild correlation for boys ( $\mathrm{r}_{\text {diast }}=0.15, \mathrm{p}<0.001$ ) but no significant relationship for girls $\left(r_{\text {diast }}=-0.01, p>0.05\right)$.

Comparing BP of those whose parents had hypertension with that of those who had no elevated BP in their family history, we found a statistically significant but clinically irrelevant difference (table 3 ). We compared the 


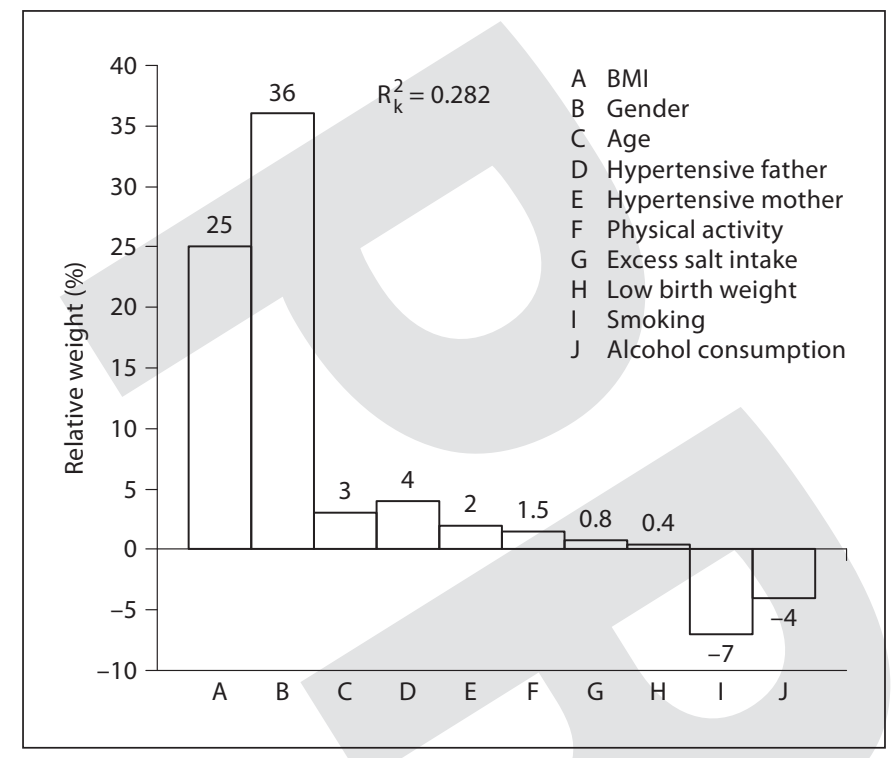

Fig. 1. Effect of examined parameters on systolic BP (multiple regression model).

BP of low-birth-weight $(<2,500 \mathrm{~g})$ adolescents with that of those those of normal birth weight. The mean BP of both groups was within the normal interval, but lowbirth-weight adolescents had a 1.8-mm Hg higher systolic BP than those in the normal birth weight control group $(\mathrm{p}=0.024)$. There were no differences in diastolic $\mathrm{BP}$ among the groups.

Neither systolic nor diastolic BP differed significantly between regular smokers and non-smokers and between those drinking alcohol on a weekly basis and those abstaining. Adolescents working out more frequently had the same BP as those without any leisure time activity. We did not find any differences between the BP of groups with or without high salt intake, and also between those with or without frequent stress situations.

Multiple regression was used to examine the influence of the independent factors on BP. Separate models were devised to predict systolic and diastolic outcomes. Entering independents together accounted for $28.2 \%$ of the total variance in systolic and for $18.1 \%$ in diastolic BP.

Examining $\beta$ weights (the relative contribution of each factor to the dependent variable), gender $(\beta=-0.36)$ and BMI $(\beta=0.25)$ emerged as significant determinants of systolic BP (fig. 1). All other independents played smaller roles in determining BP. The $\beta$ weight informs us about the effect of a unit change in the independent variable caused by the dependent variable. Boys' systolic BP exceeded girls' values by more than $10 \mathrm{~mm} \mathrm{Hg}$.

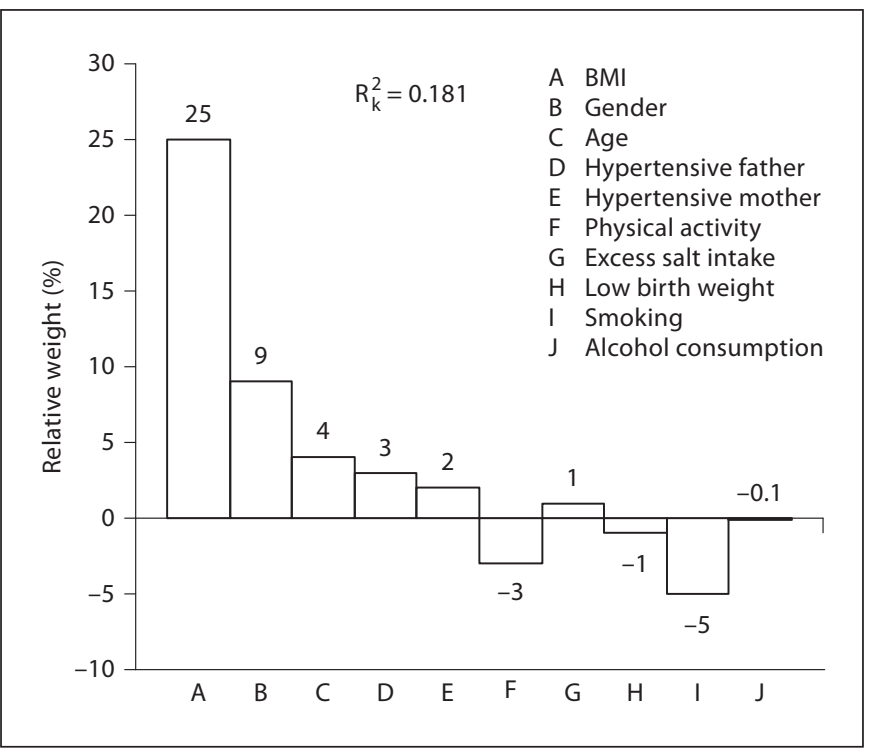

Fig. 2. Effect of examined parameters on diastolic BP (multiple regression model).

For each $1-\mathrm{kg} / \mathrm{m}^{2}$ increase in BMI, systolic BP increased by $1.17 \mathrm{~mm} \mathrm{Hg}$ as well. Hypertension of the father increased systolic BP by $1.59 \mathrm{~mm} \mathrm{Hg}$, whereas hypertension in the mother had a smaller effect (increase of systolic BP by $1.09 \mathrm{~mm} \mathrm{Hg}$ ). Increase in age (in years) elevated BP by about $0.43 \mathrm{~mm} \mathrm{Hg}$. However, smoking and alcohol consumption had opposite effects in our sample, slightly decreasing systolic BP $(1.02$ and $0.7 \mathrm{~mm} \mathrm{Hg}$, respectively) (table 4).

BMI remained an underlying independent factor of the diastolic model as well $(\beta=0.25)$, while the relative contribution of gender was smaller $(\beta=-0.09)$ (fig. 2). In the diastolic model, being a girl lowered diastolic BP only by $1.65 \mathrm{~mm} \mathrm{Hg}$. Each $1-\mathrm{kg} / \mathrm{m}^{2}$ increase in BMI increased diastolic BP by $0.75 \mathrm{~mm} \mathrm{Hg}$. While paternal hypertension increased diastolic BP by $0.92 \mathrm{~mm} \mathrm{Hg}$, maternal hypertension raised it by $0.66 \mathrm{~mm} \mathrm{Hg}$. A unit increase in age elevated BP by $0.35 \mathrm{~mm} \mathrm{Hg}$, while smoking and drinking alcohol decreased BP by $0.5 \mathrm{~mm} \mathrm{Hg}$, respectively. Interestingly though, low birth weight, exercise, salt intake and stressful life had no significant influence on either systolic or diastolic BP.

A multiple regression model was also performed in the two gender groups. The results are summarized in table 5. Entering independents together accounted for 27 and $19 \%$ of the total variance in systolic and diastolic BP in boys and 20 and $22 \%$ in girls. Among the factors studied, the $\beta$ weight of BMI was the most important deter- 
Table 4. Factors influencing BP: multiple regression model

\begin{tabular}{|c|c|c|c|c|c|c|}
\hline \multirow[t]{2}{*}{ Examined variables } & \multicolumn{3}{|c|}{ Systolic BP } & \multicolumn{3}{|c|}{ Diastolic BP } \\
\hline & $\mathrm{b}$ & $\beta$ & $\mathrm{p}$ & $\mathrm{b}$ & $\beta$ & $\mathrm{p}$ \\
\hline BMI & 1.17 & 0.25 & $<0.001$ & 0.75 & 0.25 & $<0.001$ \\
\hline Gender & -10.41 & -0.36 & $<0.001$ & -1.65 & -0.09 & $<0.001$ \\
\hline Age & 0.43 & 0.03 & 0.001 & 0.35 & 0.04 & 0.001 \\
\hline Hypertensive mother & 1.09 & 0.02 & 0.008 & 0.66 & 0.02 & 0.02 \\
\hline Hypertensive father & 1.59 & 0.04 & $<0.001$ & 0.92 & 0.03 & 0.007 \\
\hline Excess salt intake & 0.22 & 0.008 & 0.33 & 0.29 & 0.01 & 0.06 \\
\hline Physical activity & -0.33 & -0.015 & 0.11 & -0.44 & -0.03 & 0.002 \\
\hline Smoking & -1.02 & -0.07 & $<0.001$ & -0.52 & -0.05 & $<0.001$ \\
\hline Alcohol consumption & -0.70 & -0.04 & 0.001 & -0.46 & -0.03 & 0.002 \\
\hline Low birth weight & 0.17 & 0.004 & 0.59 & -0.32 & -0.01 & 0.14 \\
\hline Frequent stress situations & 0.03 & 0.003 & 0.69 & -0.01 & -0.001 & 0.85 \\
\hline
\end{tabular}

Results reflect the state after excluding extreme cases.

Table 5. Factors influencing boys' and girls' BP: multiple regression model

\begin{tabular}{|c|c|c|c|c|c|c|c|c|c|c|c|c|}
\hline & \multicolumn{6}{|c|}{ Systolic BP } & \multicolumn{6}{|c|}{ Diastolic BP } \\
\hline & \multicolumn{3}{|l|}{ girls } & \multicolumn{3}{|l|}{ boys } & \multicolumn{3}{|l|}{ girls } & \multicolumn{3}{|l|}{ boys } \\
\hline & $\mathrm{b}$ & $\beta$ & $\mathrm{p}$ & $\mathrm{b}$ & $\beta$ & $\mathrm{p}$ & $\mathrm{b}$ & $\beta$ & $\mathrm{p}$ & $\mathrm{b}$ & $\beta$ & $\mathrm{p}$ \\
\hline BMI & 1.02 & 0.25 & 0.001 & 1.42 & 0.39 & 0.001 & 0.83 & 0.09 & 0.001 & 0.63 & 0.26 & 0.001 \\
\hline Age & -0.65 & -0.54 & 0.09 & 0.68 & 0.06 & 0.15 & 0.12 & 0.16 & 0.62 & 0.42 & 0.06 & 0.13 \\
\hline Hypertensive mother & 0.95 & 0.04 & 0.08 & 0.17 & 0.07 & 0.83 & 0.85 & 0.06 & 0.04 & 0.65 & 0.07 & 0.02 \\
\hline Hypertensive father & 1.27 & 0.11 & 0.007 & 1.41 & 0.08 & 0.01 & 0.35 & 0.02 & 0.45 & 0.81 & 0.05 & 0.06 \\
\hline Excess salt intake & 2.02 & 0.67 & 0.001 & -1.16 & -0.05 & 0.15 & 1.43 & 0.10 & 0.001 & -0.28 & -0.02 & 0.60 \\
\hline Physical activity & -1.08 & 0.06 & 0.65 & -1.19 & -0.06 & 0.07 & -0.26 & -0.02 & 0.49 & -0.91 & -0.08 & 0.04 \\
\hline Smoking & -1.41 & -0.12 & 0.001 & -1.01 & -0.08 & 0.04 & -0.67 & -0.08 & 0.02 & -0.97 & -0.11 & 0.005 \\
\hline Alcohol consumption & -0.93 & -0.05 & 0.14 & -0.07 & -0.04 & 0.92 & 0.43 & 0.04 & 0.30 & 0.63 & 0.05 & 0.19 \\
\hline Low birth weight & 0.74 & 0.02 & 0.58 & -2.63 & -0.06 & 0.08 & -0.02 & -0.01 & 0.98 & -0.78 & -0.03 & 0.45 \\
\hline Stress situations & 0.65 & 0.05 & 0.16 & 1.55 & 0.09 & 0.006 & 0.52 & 0.05 & 0.09 & 0.30 & 0.03 & 0.44 \\
\hline
\end{tabular}

Results reflect the state after excluding extreme cases.

minant of systolic and diastolic BP both in boys and in girls. Other factors that also played a significant role in both genders were family history of hypertension, salt intake and smoking habit.

\section{Discussion}

The aim of the study was to implement a populationbased hypertension screening in Central-Eastern Europe, which involved more than 10,000 adolescents be- tween 15 and 18 years of age. We collected data on the prevalence of factors influencing BP, examined associations among these factors and $\mathrm{BP}$, and developed a predictive model of factors determining adolescent BP.

The average BP of boys in our study was higher (systolic $+11.3 \mathrm{~mm} \mathrm{Hg}$, diastolic $+2.2 \mathrm{~mm} \mathrm{Hg}$ ) than that of girls. Our study supported the view that geographical factors cause differences between genders. Compared to the guidelines from the USA, we found only a smaller difference in systolic BP $(5 \mathrm{~mm} \mathrm{Hg})$ and the same difference in diastolic BP (2 $\mathrm{mm} \mathrm{Hg})$ for boys [2, 3]. Investigators from 
Israel reported an even greater discrepancy (systolic 11 $\mathrm{mm} \mathrm{Hg}$, diastolic $6 \mathrm{~mm} \mathrm{Hg}$ ) [27]. Another team from Australia reported a $14 \mathrm{~mm} \mathrm{Hg}$ difference in systolic BP only for boys [14]. In Belgium there was a $3 \mathrm{~mm} \mathrm{Hg}$ systolic difference, without any in diastolic BP [28]. A recent epidemiological study from Spain found boys' systolic BP higher by $7 \mathrm{~mm} \mathrm{Hg}$ and diastolic by $2 \mathrm{~mm} \mathrm{Hg}$ than girls' [29], while a study from Saudi Arabia showed opposite trends: girls had higher $\mathrm{BP}$ (systolic $+5 \mathrm{~mm} \mathrm{Hg}$, diastolic $+2 \mathrm{~mm} \mathrm{Hg}$ ) [30].

Similar to the literature $[11,15,16,18]$, we observed a significant positive relationship between $\mathrm{BP}$ and weight, height and BMI, the association being stronger for systolic BP. Relations between weight and BP are causal: obesity is largely responsible for elevated BP. There are several times more overweight people in the hypertensive than in the normotensive population. Ostchega et al. [18] found the odds ratio for hypertension among overweight and obese boys 9.62, while 2.33 for girls, while others reported 4.33 and 4.01, respectively [13]. On the basis of a recent epidemiological study conducted in a rapidly developing country, in adolescents the prevalence of hypertension was 2 and 3-4 times more frequent among overweight and obese subjects [16].

The guidelines published in 1996, based on the data from the USA [3], observed a $2-3 \mathrm{~mm} \mathrm{Hg}$ annual increase regarding the systolic BP of boys. A recently published study found gender difference between BP increment per year in adolescents (boys 3.6/2.1 mm Hg, girls $1.5 / 1.2 \mathrm{~mm}$ $\mathrm{Hg}$ ) [29]. There is a positive linear correlation between age and BP. The correlation coefficients were 0.66 (boys) and 0.58 (girls) for the systolic and 0.53 (boys) and 0.45 for the diastolic BP [30]. In contrast, with reference to our own study, associations between either systolic or diastolic BP and age were explicitly small. Separate analyses for the different genders revealed that no significant increase in BP occurred in girls between 15 and 18 years of age in our sample. In the case of boys, there was a mild to moderate positive correlation between BP and age. Results indicate that early maturation (and the elevation of $\mathrm{BP})$, especially in girls, must now be taking place much earlier than a few decades ago.

According to data gathered from most studies, hypertension in adulthood is more frequent in children of hypertensive parents. In a recent study, hypertensive adolescents were about twice more likely to have a family history of hypertension compared to their normotensive counterparts [31]. For adolescents investigated in the Debrecen Hypertension Study, BP was statistically increased when family history was considered, however this differ- ence did not translate into meaningful clinical importance. Presumably, marked distinctions in BP observed in adolescence keep increasing during this period of time, and become more pronounced by adulthood.

Brenner et al. [21] reported an inverse relationship between decreased nephron count accompanied by low birth weight and the risk of hypertension. In recent years, numerous investigators have confirmed both the negative correlation between birth weight and BP of adolescents $[14,23]$ and the higher incidence of hypertension in adults with a low birth weight $[32,33]$. In the present study, we could not observe such a correlation between the actual BP and birth weight of adolescents. Systolic BP for 15- to 18-year-old subjects with a low birth weight was on average $2 \mathrm{~mm} \mathrm{Hg}$ higher than for those with normal birth weight, while the diastolic values showed no difference.

There were increased BP and more hypertensive individuals among those with no regular physical activity $[14$, 34]. The influence of smoking and alcohol consumption on a population level is not well defined in the 15- to 18year age group. In some studies, smoking was associated with an elevated $\mathrm{BP}$ in adolescence, too [34, 35]. Others observed a higher BP among those consuming alcohol on a weekly basis $[14,36]$. However, we did not find elevated $\mathrm{BP}$ in the presence of the above-mentioned risk factors (lack of physical activity, smoking, alcohol consumption, poor social conditions, etc.), which may partly be explained by the relatively short exposure time.

Following suggestions in the literature, we developed a multiple regression model with ten independent factors to evaluate the relative influence of each factor in determining BP. Other investigators have emphasized the role of BMI as a central determinant $[11,14,16,18]$. In our analysis, BMI emerged as a critical factor; however, gender gained more relative weight as a determinant of systolic BP. As in other studies, our findings suggested that - both for systolic and diastolic BP - the role of BMI was of extreme importance; a unit change in BMI caused systolic BP to increase by $1.17 \mathrm{~mm} \mathrm{Hg}$, while diastolic BP rose by $0.75 \mathrm{~mm} \mathrm{Hg}$. The factor that influenced systolic $\mathrm{BP}$ the most was gender in our model: boys' systolic BP was more than $10 \mathrm{~mm} \mathrm{Hg}$ higher than that of girls. Age and parental hypertension mildly influenced adolescent BP, while low birth weight had no effect. Interestingly enough, smoking and alcohol consumption slightly decreased BP of adolescents in this study. Although this difference reached statistical significance, the clinical effect was negligible. On the other hand, due to the short exposure time we have not been able to draw any conclusions 
with respect to long-term effects of lifestyle variables. We also have to mention that adolescents were asked not to smoke at least $1 \mathrm{~h}$ before the measurements. We tried to get data about the excess salt intake, stress situations and workout activity. In our study these factors did not influence systolic and diastolic BP outcomes of students in Debrecen. In addition to the short exposure time, this result can be explained also by the fact that all individuals in this population attended secondary school and participated in similar physical and free time activities. This suggests that the teenage population is still homogenous with respect to the above-mentioned factors. Moreover - not given the opportunity to measure it quantitatively - their answers contained subjective opinions. Using the above ten factors, we successfully accounted for $28 \%$ of the variance in systolic and $18 \%$ of the variance in diastolic BP. Analysis of determining factors' variance among boys and girls showed similar results (19-27\%). The huge unexplained variance points to our knowledge deficit about other key determinants (environmental, genetic factors), which are probably missed when studying adolescent hypertension.

Among factors influencing BP, BMI was of the greatest significance. In terms of systolic BP, we demonstrated that gender differences need special consideration. Adolescent $\mathrm{BP}$ is also a function of a family history of hypertension, as well as age, although the latter was shown to have less influence in this study. Our findings underline the clinical importance of the BMI and consequently individual weight, which is modifiable, and a reduction in this factor leads to better outcomes. Reducing body weight results in a significant decrease in $\mathrm{BP}$, suggesting that people with moderate hypertension and proper weight management could be treated without medication.

We have to mention the limitations of the study. We tried to obtain data about the numbers of cigarettes or alcoholic drinks as well as frequency of physical activity and salt intake in our questionnaire, but in order to simplify the answers, semiquantitative ratings were offered, which can decrease the quality of the data. In comparison to age and weight, these factors do not represent the same relevant and exact value. On the other hand, the adolescents in our study could fill in the data with the help of their parents, therefore they probably did not always dare to write their real answers on smoking habits and alcohol consumption.

\section{References}

1 Lurbe E, Cifkova R, Cruickshank JK, Dillon MJ, Ferreira I, Invitti C, et al: Management of high blood pressure in children and adolescents: recommendations of the European Society of Hypertension. J Hypertens 2009; 27:1719-1742

2 National High Blood Pressure Education Program Working Group on High Blood Pressure in Children and Adolescents. The fourth report on the diagnosis, evaluation, and treatment of high blood pressure in children and adolescents. Pediatrics 2004;114: 555-576.

3 National High Blood Pressure Education Program Working Group on Hypertension Control in Children and Adolescents. Update on the 1987 Task Force Report on High Blood Pressure in Children and Adolescents. Pediatrics 1996;98:649-658.

4 Pall D, Settakis G, Katona E, Csiba L, Kakuk G, Limburg M, et al: Debrecen Hypertension Study. Increased common carotid artery intima media thickness in adolescent hypertension: results from the Debrecen Hypertension Study. Cerebrovasc Dis 2003;15:167172.

Factors Influencing Adolescent BP -

The Debrecen Hypertension Study
5 Israeli E, Korzets Z, Tekes-Manova D, Tirosh A, Schochat T, Bernheim J, et al: Blood-pressure categories in adolescence predict development of hypertension in accordance with the European guidelines. Am J Hypertens 2007;20:705-709.

6 Chen X, Wang Y: Tracking of blood pressure from childhood to adulthood: a systematic review and meta-regression analysis. Circulation 2008; 117:3171-3180.

7 Gillman MW, Cook NR: Blood pressure measurement in childhood epidemiological studies. Circulation 1995;92:1049-1057.

8 Goonasekera CD, Dillon MJ: Measurement and interpretation of blood pressure. Arch Dis Child 2000;82:261-265.

9 Pall D, Katona E, Fulesdi B, Zrínyi M, Zatik J, Bereczki D, et al: Blood pressure distribution in a Hungarian adolescent population: comparison with normal values in the USA. J Hypertens 2003;21:41-47.

10 Sharma BK, Sagar S, Wahi PL, Talwar KK, Singh S, Kumar L: Blood pressure in schoolchildren in northwest India. Am J Epidemiol 1991;134:1417-1426.

11 Sorof JM, Lai D, Turner J, Poffenbarger T, Portman RJ: Overweight, ethnicity, and the prevalence of hypertension in school-aged children. Pediatrics 2004;113:475-482.
12 Harrabi I, Belarbia A, Gaha R, Essoussi AS, Ghannem H: Epidemiology of hypertension among a population of school children in Sousse, Tunisia. Can J Cardiol 2006;22:212216.

13 Moore WE, Eichner JE, Cohn EM, Thompson DM, Kobza CE, Abbott KE: Blood pressure screening of school children in a multiracial school district: the Healthy Kids Project. Am J Hypertens 2009;22:351-356.

14 Milligan RA, Burke V, Dunbar DL, Spencer M, Balde E, Beilin LJ, Gracey MP: Associations between lifestyle and cardiovascular risk factors in 18-year-old Australians. J Adolesc Health 1997;21:186-195.

15 Nur N, Cetinkaya S, Yilmaz A, Ayvaz A, Bulut MO, Sümer H: Prevalence of hypertension among high school students in a middle Anatolian province of Turkey. J Health Popul Nutr 2008;26:88-94.

16 Chiolero A, Madeleine G, Gabriel A, Burnier M, Paccaud F, Bovet P: Prevalence of elevated blood pressure and association with overweight in children of a rapidly developing country. J Hum Hypertens 2007;21:120-127.

17 Hansen ML, Gunn PW, Kaelber DC: Underdiagnosis of hypertension in children and adolescents. JAMA 2007;22;298:874-879. 
18 Ostchega Y, Carroll M, Prineas RJ, McDowell MA, Louis T, Tilert T: Trends of elevated blood pressure among children and adolescents: data from the National Health and $\mathrm{Nu}$ trition Examination Survey 1988-2006. Am J Hypertens 2009;22:59-67.

19 Himmelmann A, Svensson A, Hansson L: Blood pressure and left ventricular mass in children with different maternal histories of hypertension: the Hypertension in Pregnancy Offspring Study. J Hypertens 1993;11: 263-268.

20 Mo R, Omvik P, Lund-Johansen P: The Bergen Blood Pressure Study. Offspring of two hypertensive parents have significantly higher blood pressures than offspring of one hypertensive and one normotensive parent. J Hypertens 1995;13:1614-1617.

21 Brenner BM, Garcia DL, Anderson S: Glomeruli and blood pressure. Less of one, more the other? Am J Hypertens 1988;1:335347.

22 Hardy R, Sovio U, King VJ, Skidmore PM, Helmsdal G, Olsen SF, et al: EURO-BLCS Study Group. Birthweight and blood pressure in five European birth cohort studies: an investigation of confounding factors. Eur J Public Health 2006;16:21-30.

23 Barker DJ, Osmond C, Forsen TJ, Kajantie E, Eriksson JG: Maternal and social origins of hypertension. Hypertension 2007;50:565571
24 Pall D, Katona E, Fulesdi B, Zrinyi M, Takacs E, Polgar P, Kakuk G: Blood pressure values of high school students in Debrecen. The Debrecen Hypertension Study: methodological procedures and initials results. Hypertens Nephrol 2001;5:237-243.

25 Stergiou GS, Yiannes NG, Rarra VC: Validation of the Omron 705 IT oscillometric device for home blood pressure measurement in children and adolescents: the Arsakion School Study. Blood Press Monit 2006;11: 229-234.

26 Coleman A, Freeman P, Steel S, Shennan A Validation of the Omron 705IT (HEM759-E) oscillometric blood pressure monitoring device according to the British Hypertension Society protocol. Blood Press Monit 2006;11:27-32.

27 Jaber L, Eisenstein B, Shohat M: Blood pressure measurements in Israeli Arab children and adolescents. Isr Med Assoc J 2000;2:118121.

28 Paulus D, Saint-Remy A, Jeanjean M: Blood pressure during adolescence: a study among Belgian adolescents selected from a high cardiovascular risk population. Eur J Epidemiol 1999;15:783-90.

29 Cordente-Martínez CA, García-Soidán P, Sillero-Quintana M, Stirling JR: Correlations between the blood pressure and other health variables in Spanish adolescents. Int J Adolesc Med Health 2009;21:635-651.
30 Soyannwo MA, Kurashi NY, Gadallah M, Hams J, el-Essawi O, Khan NA, Singh RG, Alamri A, Beyari TH: Blood pressure pattern in Saudi population of Gassim. Afr J Med Med Sci 1998;27:107-116.

31 Mijinyawa MS, Iliyasu Z, Borodo MM: Prevalence of hypertension among teenage students in Kano, Nigeria. Niger J Med 2008; 17: 173-178.

32 Keijzer-Veen MG, Finken MJ, Nauta J, Dekker FW, Hille ET, Frölich M, et al: Dutch POPS-19 Collaborative Study Group. Is blood pressure increased 19 years after intrauterine growth restriction and preterm birth? A prospective follow-up study in The Netherlands. Pediatrics 2005;116:725-731.

33 Hovi P, Andersson S, Räikkönen K, StrangKarlsson S, Järvenpää AL, Eriksson JG, et al: Ambulatory blood pressure in young adults with very low birth weight. J Pediatr 2010; 156:54-59.

34 Kollias A, Antonodimitrakis P, Grammatikos E, Chatziantonakis N, Grammatikos EE, Stergiou GS: Trends in high blood pressure prevalence in Greek adolescents. J Hum Hypertens 2009;23:385-390.

35 Flouris AD, Faught BE, Klentrou P: Cardiovascular disease risk in adolescent smokers: evidence of a 'smoker lifestyle'. J Child Health Care 2008;12:221-231.

36 Jorgensen RS, Maisto SA: Alcohol consumption and prehypertension: an investigation of university youth. Behav Med 2008;34:21-28. 